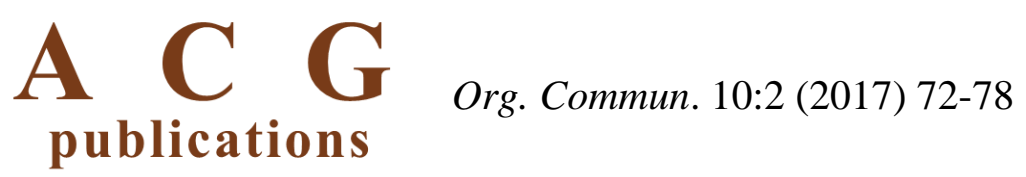

organic communications

\title{
Formation of bioactive benzofuran via oxidative coupling, using coconut water (Cocos nucifera $\mathrm{L}$.) as biocatalyst
}

\section{Luís Cezar Rodrigues ${ }^{1}$, José Maria Barbosa-Filho², Sany Delany Gomes Marques $^{3}$, Flávio Valadares Pereira Borges ${ }^{3}$, Luiz André de Araújo Silva ${ }^{3}$, Irma Herrera Bravo de Laguna ${ }^{4}$ and Roberto Mioso ${ }^{5 *}$}

\author{
${ }^{1}$ Post-Graduation Program in Development and Technological Innovation in Medicines, Department \\ of Biotechnology, Biotechnology Research Center, Federal University of Paraíba, João Pessoa, PB, \\ 58051-970, Brazil \\ ${ }^{2}$ Department of Pharmaceutical Sciences, Biotechnology Center, Federal University of Paraíba, João \\ Pessoa, PB, 58051-970, Brazil \\ ${ }^{3}$ Post-Graduation Program in Development and Technological Innovation in Medicines, Federal \\ University of Paraíba, João Pessoa, PB, 58051-970, Brazil \\ ${ }^{4}$ Department of Biology, University of Las Palmas de Gran Canaria, Las Palmas de Gran Canaria, \\ 35017, Spain \\ ${ }^{5}$ Department of Biochemistry, Federal University of Pernambuco, \\ Recife, PE, 50670-901, Brazil
}

(Received November 22, 2016; Revised January 26, 2017; Accepted February 10, 2017)

\begin{abstract}
The capacity of simple coconut water, which contains natural peroxidases, to act as a biocatalyst for the oxidative coupling-cyclization of $p-(\mathrm{OH})$-phenylpropanoids, was evaluated in this work. As a result, dimeric forms of isoeugenol (licarin A) and methyl p-coumarate (methyl dehydrodicoumarate) were obtained. The products of the reactions were characterized by optical rotatory dispersion, and ${ }^{1} \mathrm{H}$-NMR and ${ }^{13} \mathrm{C}-\mathrm{NMR}$ spectroscopy. The oxidative coupling-cyclization mechanism for coniferyl alcohol is proposed.
\end{abstract}

Keywords: Bioprocess; biotransformation; neolignans; peroxidase; Cocos nucifera. ㄷ 2017 ACG Publications. All rights reserved.

\section{Introduction}

Peroxidases (PODs) include a group of enzymes belonging to the subclass of oxidoreductases (E.C. 1.11.1.7), which are widely found in nature ${ }^{1,2}$. These biocatalysts are an emerging eco-friendly alternative that can be used in oxidative reactions, given that their selectivity is superior to that of other chemocatalysts. Moreover, the enzymatic treatment efficiency seems to be independent of the enzyme purity; therefore, it is possible to utilize a crude enzyme preparation instead of a purified one, thus minimizing chemical production costs ${ }^{3}$.

The reduction of peroxides at the expense of electron-donating substrates makes PODs useful in a number of biotechnological applications. ${ }^{4}$. These enzymes have shown potential for the biotransformation of a broad range of aromatic chemicals; for example, in the synthesis of: tetracyclic

\footnotetext{
${ }^{*}$ Corresponding author: E-Mail: robertomioso@yahoo.co.uk
} 
heterocycles (e.g., coumestans and benzofuroquinolinones), with the use of PODs from raw onion extract ${ }^{5}$; dihydrobenzofuran lignans, with the use of PODs from horseradish ${ }^{6}$; and O- $p$ dehydroguaiacol, biocatalyzed by PODs extracted from Brassica oleracea ${ }^{7}$.

Besides microorganisms and animals, natural sources of these enzymes include papaya (Carica papaya), banana (Musa paradisiaca), sweet flag (Acorus calamus), and coconut (Cocos nucifera $)^{8-10}$, among other plants. Coconut fruit, particularly, contains in its endocarp significant amount of active enzymes and its use as a biocatalyst - for reduction and hydrolytic reaction processes is, apparently, an opportunity for developing a new area of synthetic organic chemistry ${ }^{11,12}$.

In oxidative coupling reactions, for example, the process occurs between two $p-(\mathrm{OH})$ phenylpropanoid units, in which the presence of at least one free phenolic hydroxyl is necessary ${ }^{13}$. The reaction is catalyzed by the PODs present in the liquid endosperm of the coconut. The oxidation of the substrate is accomplished through the reduction of the porphyrinic iron from the active site, and the reactivation of the peroxidase through the reoxidation of the iron and the decomposition of the hydrogen peroxide into water. Accordingly, it was observed that some studies show the use of the right concentration of the hydrogen peroxide, because an excessive amount may inhibit the oxidative action from the enzyme. A pH of between 5.0 and 7.0 for the coconut water is ideal for good oxidative performance, thus avoiding the need for adjustment ${ }^{14}$.

Rodrigues and Barbosa-Filho described an interesting biocatalytic oxidation process using coconut water as a reaction medium and PODs sources ${ }^{15}$. According to these authors, when equimolar amounts of hydrogen peroxide solution (oxygenated water at $10 \%(v / v)$ or $3 \%$ by weight) and $p-(\mathrm{OH})$ phenylpropanoid are added to the coconut water, after a few minutes the formation of the oxidative coupling of stereospecific phenylpropanoid units can be seen. As a result, (-)-licarin A - which is a known neolignan that displays antileishmanial activity associated with immunomodulatory effects ${ }^{16}$, was obtained selectively and at satisfactory yields (Scheme 1).

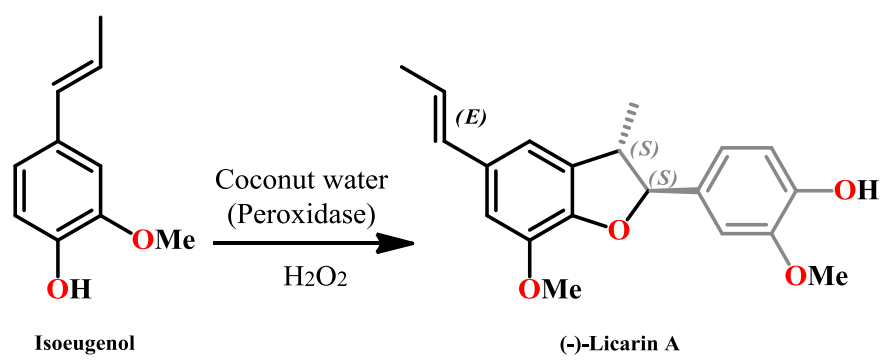

Scheme 1. Synthesis of (-)-Licarin A via coconut water catalyst.

The aim of this work was to report on the biocatalytic oxidative process using coconut water from green coconuts (Cocos nucifera L.) as a liquid medium and natural source of peroxidases. The crude enzymes were used as a biocatalyst to access the dimeric forms of isoeugenol (licarin A) and methyl $p$-coumarate (methyl dehydrodicoumarate). The products of the reactions were characterized by optical rotatory dispersion and ${ }^{1} \mathrm{H}$ - and ${ }^{13} \mathrm{C}-\mathrm{NMR}$ spectroscopy.

\section{Materials and Methods}

\subsection{Coconut water source}

Coconut water was obtained from green coconuts (5-6 months old) which contained very little coconut flesh (jelly-like). All of the coconuts, which were of the Green Dwarf variety common in Brazil, were purchased from a local market located in the city of João Pessoa, Paraíba State. 


\subsection{Preparation of (-) licarin A}

Water from four green coconuts was collected, and all of the liquid measured gave $1.6 \mathrm{~L}$ of coconut water, which was then filtered through cotton mesh into a glass funnel. The coconut water was transferred to a 2 L Erlenmeyer flask containing a magnetic bar. A stirrer plate was fitted, and with the reaction medium being magnetically stirred, a solution of $1 \mathrm{~g}$ of isoeugenol in $10 \mathrm{~mL}$ of methanol was added. Through an automatic syringe, an aqueous hydrogen peroxide solution $3 \%(w / v)$ was slowly added $\left(3 \mathrm{~mL}^{-1}\right)$ to reach a total of $13.8 \mathrm{~mL}$, which was kept under magnetic stirring for 1 $\mathrm{h}$, then $0.5 \mathrm{~L}$ of dichloromethane was added and the solution was magnetically stirred for a further 10 min. The mixture was transferred to a separatory funnel and it was extracted with $500 \mathrm{~mL}(2 \mathrm{x})$ of $\mathrm{CH}_{2} \mathrm{Cl}_{2}$. Dichloromethane phases were combined and dried with anhydrous magnesium sulfate, and then filtered. After the solvent removal by rotaevaporation, the resulting residue was purified by preparative silica gel column chromatography, using as eluent a mixture of hexane and ethyl acetate (80:20 ratio). Subsequently, $0.55 \mathrm{~g}$ of (-)-licarin A was obtained at 55\% yield in the form of white crystals, with a melting point of $108{ }^{\circ} \mathrm{C}\left(\mathrm{CHCl}_{3}\right) \cdot \alpha_{D}^{25}=-20^{\circ}\left(\mathrm{CHCl}_{3} ; c 1.0\right)$ (Scheme 2). ${ }^{1} \mathrm{H}-\mathrm{NMR}(\delta$, $\left.200 \mathrm{MHz}, \mathrm{CDCl}_{3}\right): 6.96\left(1 \mathrm{H}, \mathrm{s}, \mathrm{H}-6^{\prime}\right), 6.88\left(2 \mathrm{H}, \mathrm{s}, \mathrm{H}-2^{\prime}\right.$ and H-5'), $6.77(1 \mathrm{H}, \mathrm{s}, \mathrm{H}-6), 6.75(1 \mathrm{H}, \mathrm{s}, \mathrm{H}-2)$, $6.36(1 \mathrm{H}, \mathrm{d}, \mathrm{H}-\alpha, J=15.7), 6.09(1 \mathrm{H}, \mathrm{dq}, \mathrm{H}-\beta, J=15.7$ and $6.6 \mathrm{~Hz}), 5.64(1 \mathrm{H}, \mathrm{s}, \mathrm{OH}), 5.08(1 \mathrm{H}, \mathrm{d}, \mathrm{H}-$ $\left.\alpha^{\prime}, J=9.5 \mathrm{~Hz},\right), 3.88\left(3 \mathrm{H}, \mathrm{s}, \mathrm{OC}_{\mathrm{H}}\right), 3.86\left(3 \mathrm{H}, \mathrm{s}, \mathrm{OC}_{3}\right), 3.43\left(1 \mathrm{H}, \mathrm{dq}, \mathrm{H}-\beta^{\prime}, J=9.5\right.$ and $\left.6.8 \mathrm{~Hz}\right), 1.86$ $(3 \mathrm{H}, \mathrm{dd}, \mathrm{H} \lambda, J=6.6$ and $1.7 \mathrm{~Hz}), 1.36\left(3 \mathrm{H}, \mathrm{d}, \mathrm{H} \lambda^{\prime}, J=6.8 \mathrm{~Hz}\right) .{ }^{13} \mathrm{C}-\mathrm{NMR}\left(\delta, 50.3 \mathrm{MHz}, \mathrm{CDCl}_{3}\right)$ : 146.60 (C4), 146.48 (C5'), 145.70 (C5), 144.08 (C4'), 133.20 (C3), 132.13 (C1'), 132.00 (C1), 130.87 (C $\alpha$ ), $123.44(\mathrm{C} \beta), 119.93$ (C2'), 114.00 (C3'), 113.23 (C2), 109.10 (C6), 108.83 (C6'), 93.72 (C $\left.\alpha^{\prime}\right)$, $55.89(\mathrm{OMe}), 45.60\left(\mathrm{C} \beta^{\prime}\right), 18.39(\mathrm{C} \lambda), 17.50\left(\mathrm{C} \lambda^{\prime}\right)$.

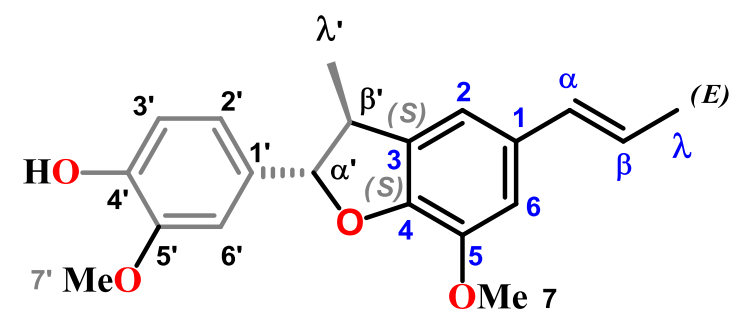

Scheme 2. Preparation of (-) - licarin A, with the phenylpropanoid units highlighted.

\subsection{Preparation of methyl (-)-dehydrodicumarate}

$p$-(OH)-cumaric acid (1.0 g) was previously esterified into the methyl cumarate and subjected to the same oxidative process to provide $0.4 \mathrm{~g}$ of methyl dehydrodicumarate with $40 \%$ yield (Scheme 3). ${ }^{1} \mathrm{H}-\mathrm{NMR}\left(\delta, 200 \mathrm{MHz}, \mathrm{CDCl}_{3}\right): 7.64(1 \mathrm{H}, \mathrm{d}, J=15.8 \mathrm{~Hz}, \mathrm{H}-\alpha), 7.52(1 \mathrm{H}, \mathrm{br} \mathrm{s}, \mathrm{H}-2), 7.39(1 \mathrm{H}, \mathrm{d}, J$ $=8.0, \mathrm{H}-6), 7.22\left(2 \mathrm{H}, \mathrm{d}, J=8.4, \mathrm{H}-2^{\prime}\right.$ and $\left.\mathrm{H}-6^{\prime}\right), 6.86(1 \mathrm{H}, \mathrm{d}, J=5.4, \mathrm{H}-5), 6.82\left(2 \mathrm{H}, \mathrm{d}, \mathrm{J}=5.8, \mathrm{H}-3^{\prime}\right.$ and $\left.\mathrm{H}-5^{\prime}\right), 6.30(1 \mathrm{H}, \mathrm{d}, J=15.8, \mathrm{H}-\beta), 6.02\left(1 \mathrm{H}, \mathrm{d}, J=7.5, \mathrm{H}-\alpha^{\prime}\right), 4.26\left(1 \mathrm{H}, \mathrm{d}, J=7.5, \mathrm{H}-\beta^{\prime}\right), 3.81$ $\left(3 \mathrm{H}, \mathrm{s}, \mathrm{H}-7^{\prime}\right), 3.79(3 \mathrm{H}, \mathrm{s}, \mathrm{H}-7) .{ }^{13} \mathrm{C}-\mathrm{NMR}\left(\delta, 50.3 \mathrm{MHz}, \mathrm{CDCl}_{3}\right): 170.99\left(\mathrm{C} \lambda^{\prime}\right), 168.22(\mathrm{C} \lambda), 161.13$ (C4), $156.41\left(\mathrm{C} 4{ }^{\prime}\right), 144.91(\mathrm{C} \alpha), 131.54\left(\mathrm{C} 1^{\prime}\right), 130.86(\mathrm{C} 2), 127.63(\mathrm{C} 1), 127.44\left(\mathrm{C} 2^{\prime}\right.$ and $\left.\mathrm{C}^{\prime}\right)$, $125.02(\mathrm{C} 5), 124.96(\mathrm{C} 6), 115.87\left(\mathrm{C} 3^{\prime}\right.$ and $\left.\mathrm{C}^{\prime}\right), 115.68(\mathrm{C} \beta), 110.28(\mathrm{C} 3), 86.49(\mathrm{C} \alpha \mathrm{v}), 54.95\left(\mathrm{C} \beta^{\prime}\right)$, $52.92\left(\mathrm{C}^{\prime}\right), 51.77(\mathrm{C} 7)$. 


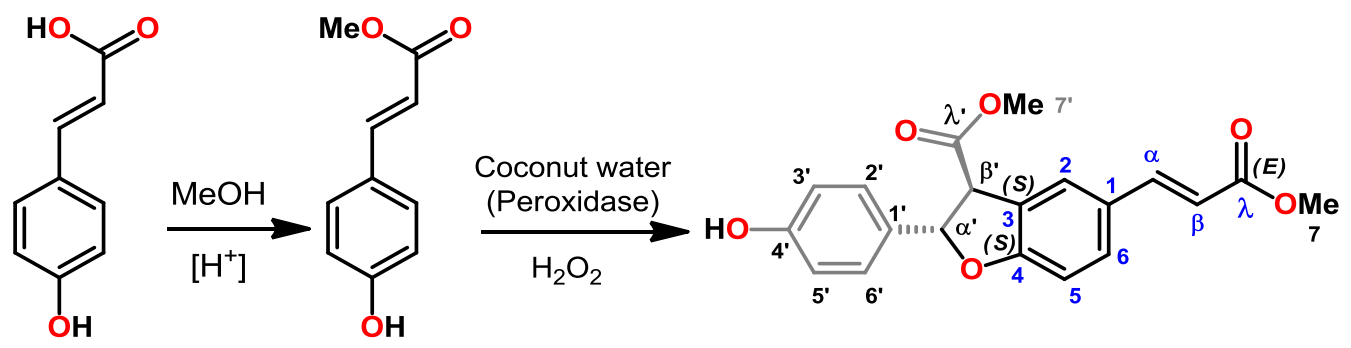

Scheme 3. Dimerizations of methyl $p$-coumarate.

\section{Results and Discussion}

\subsection{Biocatalytic oxidative coupling reaction}

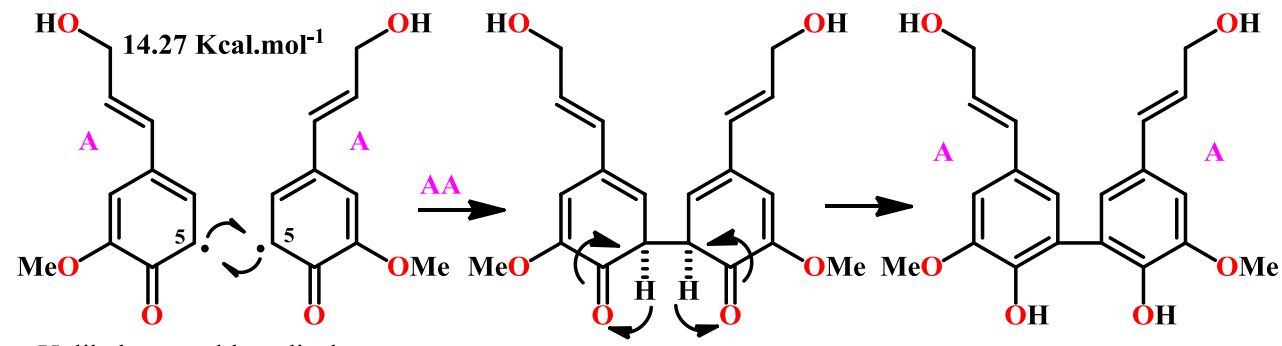

Unlikely, unstable radicals
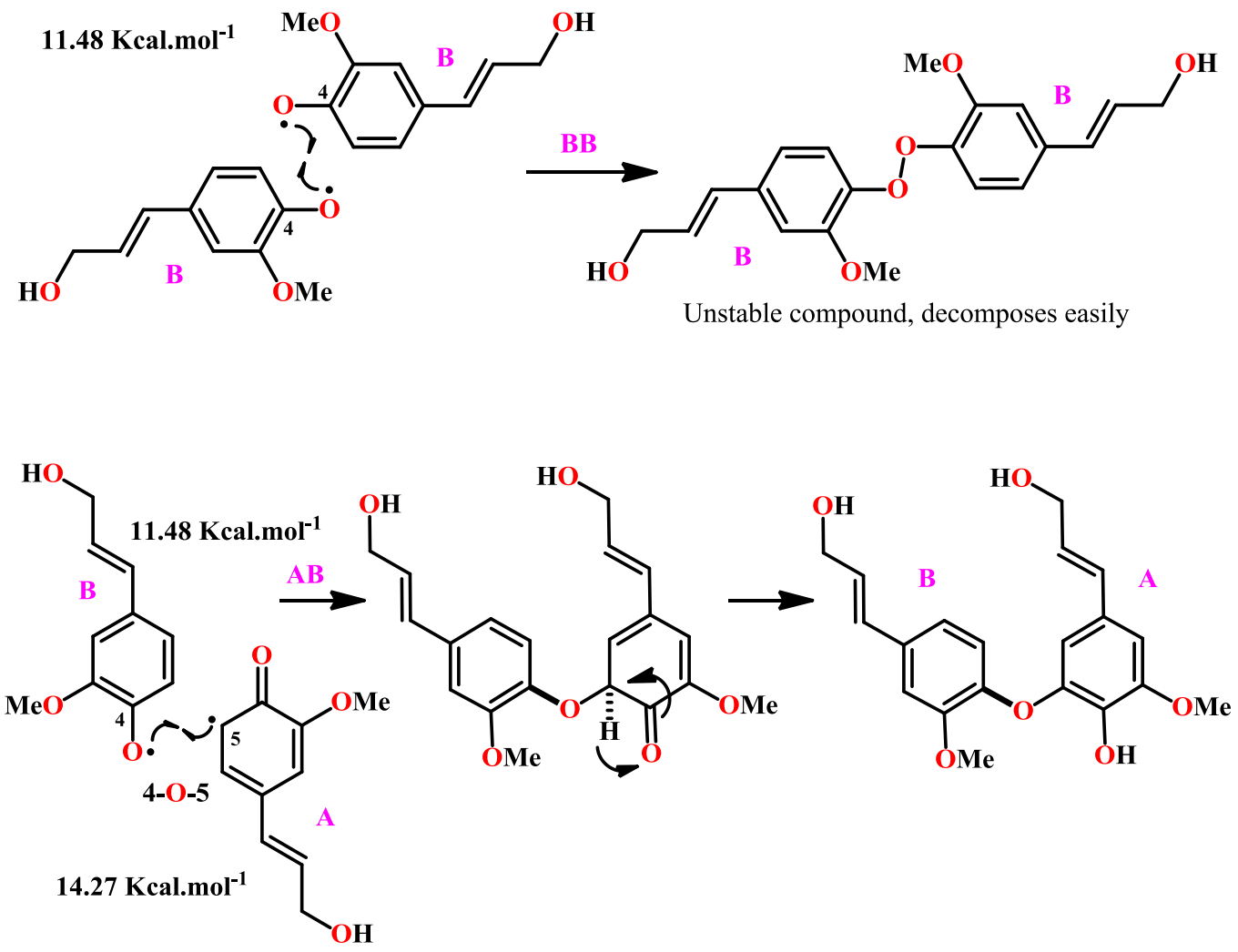

Scheme 4. Dimerizations of coniferyl alcohol. 
The biocatalytic oxidative coupling reaction (Scheme 4, above) occurs by the catalytic action of peroxidase present in coconut water, when no special condition is necessary, just magnetic stirring and an appropriate temperature. According to Henriksen et al. ${ }^{14}$, the peroxidase present in coconut water has an iron porphyrin nucleus, in which $\mathrm{Fe}^{3+}$ is oxidized to $\mathrm{Fe}^{4+}$ by hydrogen peroxide, wherein the $\mathrm{Fe}^{3+}$ form is restored when it receives a $p-(\mathrm{OH})$-phenylpropanoid electron (Scheme 2). In every catalytic cycle, a $p-(\mathrm{OH})$-phenylpropanoid unit (compound I) is used and, in each subsequent cycle, the process is repeated with the same compound or with a different a $p-(\mathrm{OH})$-phenylpropanoid molecule (i.e., compound 2). The radicals formed in these cycles have several resonant structures, with some being more stable than others (see Scheme S1, in the supplementary material).

During this reaction, the pair of enantiomers $S R$ and $R S$ of licarin A are not observed. Their formation is likely impaired by preventing the steric cis between the phenyl and methyl substituents of the hydrofuran ring. This absence is readily confirmed because the pair of $S S$ and $R R$ enantiomers is easily differentiated from its $S R$ and $R S$ diastereoisomers.

It is observed that the enzyme action point is the hydroxyl at the para position. However, its absence, replacement, or protection makes the compound inactive for the enzymatic mechanism. The various radicals formed are then available to dimerize, and various combinations are possible, with each producing a corresponding dimer.<smiles>C/C=C/c1ccc2c(c1)C(C)[C@H](c1ccc(O)cc1)O2</smiles>

(+)-Conocarpan<smiles>COc1cc([C@@H]2Oc3c(OC)cc(CCC(=O)O)cc3[C@@H]2CO)ccc1O</smiles><smiles>COc1cc([C@@H]2Oc3c(OC)cc(CCC(C)=O)cc3[C@@H]2CO)cc(OC)c1O</smiles><smiles>C/C=C/c1cc(OC)c2c(c1)C(C)[C@H](c1ccc(O)c(O)c1)O2</smiles>

Kachirachirol B<smiles>C/C=C/c1cc(OC)c2c(c1)[C@H](C)[C@H](c1ccc3c(c1)OCO3)O2</smiles>

Licarin B<smiles>C/C=C/c1cc(OC)c2c(c1)C(C)[C@H](c1cc(OC)c(O)c(OC)c1)O2</smiles>

Odoratisol A<smiles>C/C=C/c1ccc2c(c1)[C@@H](C)[C@H](c1ccc3c(c1)OCO3)O2</smiles>

Regnelline<smiles>COc1cc(CCCO)cc2c1O[C@H](c1ccc3c(c1)OCO3)C2C</smiles>

Phyllnirurin<smiles>C/C=C/c1cc(OC)c2c(c1)C(C)[C@H](c1ccc(O)cc1)O2</smiles><smiles>C/C=C/c1ccc2c(c1)C(C)[C@H](c1ccc(O)c(OC)c1)O2</smiles>

Parakmerin A<smiles>C/C=C/c1cc(OC)c2c(c1)C(C)[C@H](c1cc(O)c(O)c(O)c1)O2</smiles>

Obovatifol<smiles>C/C=C/c1cc(OC)c2c(c1)C(C)[C@H](c1ccc3c(c1)OCO3)O2</smiles>

Eupomatenoid 8

Figure 1. Some natural lignans that have not yet been synthesized. 
It is interesting to note that when a commercial peroxidase (HRP) is used in in vitro biotransformations, the reaction loses stereoselectivity forming a mixture of isomers ${ }^{17}$. This ambiguous behavior is explained by the action of an auxiliary protein that is present in the natural environment, but absent in the purified commercial enzyme. In previous studies, it was shown that synthetases present in natural extracts would be responsible for the alignment of phenoxyl radicals ${ }^{3}$. These radicals are produced primarily by the action of peroxidases (see Scheme S2, in the supplementary material).

Thus, a strategy that helps to predict coupling is provided by the stability calculations concerning the radicals, using the $a b$ initio method (HF/3-21G) via the Gaussian program (see Figure $\mathrm{S} 1$, in the supplementary material).

The more stable a radical, the greater its lifetime. Thus, the population of the most stable radicals increases in the reaction medium, and when two radicals have favorable orientation, they form the corresponding dimeric compound. In accordance with the stability calculations, the most stable radical (shown in blue in Scheme S3, in the supplementary material) is the one that participates in the majority of the reactions. If the three main radicals ( $\mathrm{A}, \mathrm{B}$ and $\mathrm{C})$ are enumerated from left to right, the possible dimerizations would be $\mathrm{AA}, \mathrm{AB}, \mathrm{BC}, \mathrm{BB}, \mathrm{BC}$, and $\mathrm{CC}$ (Schemes 4 and $\mathrm{S} 3$ ).

From the dimerizations of coniferyl, the $\mathrm{BB}$ dimer is a stable peroxide that decomposes easily, restituting the starting radicals. The AA dimer is formed by the two most energetic radicals (14.27 $\mathrm{Kcal} \cdot \mathrm{mol}^{-1}$ ), which is why it is rarely formed. The $\mathrm{AB}$ dimer is feasible and it is the fourth spot displayed in the analytical thin-layer chromatography of the reaction using the coniferyl as substrate.

The selective obtainment of (-)-licarin when using green coconut water would not be possible without the presence of any ingredient that recognizes and stereoselectively favors its formation. The most likely candidate for this approach would be an auxiliary protein that is present in the natural environment, but absent or inactive in the commercial purified peroxidase. It would capture the radicals formed by the action of the peroxidase and it would guide them to the formation of one of the enantiomers.

This proposal uses the enzyme in its natural state, accompanied by all of its cofactors and adjuvants, thus dispensing with the extraction and purification process, so that, ultimately, a better quality product is obtained than that from the imported commercial purified enzyme which is expensive.

By controlling the order, concentration, and rate of addition of the reagents, it is possible to speculate about the production of many other naturally occurring lignans. With the exception of the (+)-conocarpan, the other dimers shown in Figure 1 are novel synthesis.

Besides the lignans shown in Figure 1, which were not additionally synthesized, many other similar compounds are currently synthesized uneconomically and non-stereospecifically via many synthetic steps, particularly when one wishes to obtain a certain stereoselectivity. It is clear, therefore, that the potential of this technique has promise.

\section{Conclusions}

This present study provides additional knowledge on the capacity of simple coconut water, which contains natural peroxidases, to act as a biocatalyst for the oxidative coupling-cyclization of $p$ $(\mathrm{OH})$-phenylpropanoids. The products of the reactions, isoeugenol dimers, licarin A, and methyl $p$ coumarate (methyl dehydrodicoumarate), were obtained and characterized by optical rotatory dispersion and NMR spectroscopy. Consequently, a possible oxidative coupling-cyclization mechanism for coniferyl alcohol was proposed. It is clear, therefore, that the potential of this technique which uses natural fruits as a source of peroxidases to enhance oxidative coupling of phenolic compounds, may be of great interest to the food and pharmaceutical industry.

\section{Acknowledgments}

The authors would like to thank the Brazilian National Council for Scientific and Technological Development $(\mathrm{CNPq})$ and the Coordination for the Improvement of Higher Education Personnel (CAPES) for the M.Sc. fellowships granted to L.A.A.S. and S.D.G.M, respectively. We also would 
like to thank the Characterization and Analysis Research Center (NUCAL) of the Federal University of Paraíba (UFPB) for technical assistance and NMR spectroscopy.

\section{Supporting Information}

Supporting Information accompanies this paper on http://www.acgpubs.org/OC

\section{References}

[1] Biles, C.L.; Martyn, R.D. Peroxidase, polyphenoloxidase and shikimate dehydrogenase isozymes in relation to tissue type, maturity and pathogen induction of watermelon seedlings. Plant Physiol. Biochem.1993, 31, 499-506.

[2] Rusdi, B.; Mulyanti, D.; Rodiyah, M. Characterization of peroxidase enzyme from water spinach (Ipomoea aquatica Forsk.) fraction. Procedia Chem. 2014, 13, 170-176.

[3] Wilberg, K.Q.; Nunes, D.G.; Rubio, J. Removal of phenol by enzymatic oxidation and flotation. Braz. J. Chem. Eng. 17, 4-7.

[4] Regalado, C.; García-Almendárez , B.E.; Duarte-Vázquez, M.A. Biotechnological applications of peroxidases, Phytochem. Rev. 2004, 3, 243-256.

[5] Angeleska, S.; Kefalas, P.; Detsi, A. Crude peroxidase from onion solid waste as a tool for organic synthesis. Part III: synthesis of tetracyclic heterocycles (coumestans and benzofuroquinolinones). Tetrahedron Lett. 2013, 54, 2325-2328.

[6] Saliu, F.; Tolppa, E.L.; Zoia, L.; Orlandi, M. Horseradish peroxidase catalyzed oxidative cross-coupling reactions: the synthesis of 'unnatural' dihydrobenzofuran lignans. Tetrahedron Lett. 2011, 52, 38563860.

[7] Anita, Y.; Widiyarti, G.; Abbas, J. Synthesis and elucidation structure of O-para dehydroguaiacol prepared by crude of Brassica oleracea var alboglabra peroxidasecatalyzed oxidation. J. Appl. Pharm. Sci. 2014, 4, 62-65.

[8] Bansal, N.; Kanwar, S.S. Peroxidase(s) in environment protection. Sci. World J. 2013, ID 714639, 9.

[9] Kalsoom, U.; Bhatti, H.N.; Asgher, M. Characterization of plant peroxidases and their potential for degradation of dyes: a review. Appl. Biochem. Biotechnol. 2015, 176, 1529-1550.

[10] Duarte, A.C.P.; Coelho, M.A.Z.; Leite, S.G.F. Identification of peroxidase and tyrosinase in green coconut water, Cienc. Tecnol. Aliment. 2002, 3, 266-270.

[11] Tan, T.C.; Cheng, L.H.; Bhat, R.; Rusul, G.; Easa, A.M. Composition, physicochemical properties and thermal inactivation kinetics of polyphenol oxidase and peroxidase from coconut (Cocos nucifera) water obtained from immature, mature and overly-mature coconut. Food Chem. 2014, 142, 121-128.

[12] Fonseca, A.M.; Montea, F.J.Q.; Oliveira, M.C. F.; Mattosa, M.C.; Cordell, G.A.; Braz-Filho, R.; Lemosa, T.L.G. Coconut water (Cocos nucifera L.) -A new biocatalyst system for organic synthesis. $J$. Mol. Catal.B: Enzym. 2009, 57, 78-82.

[13] Davin, L.B. ; Wang, H.-B.; Crowell, A.L.; Bedgar, D.L.; Martin, D.M.; Sarkanen, S.; Lewis, N.G. Stereoselective bimolecular phenoxy radical coupling by an auxiliary (dirigent) protein without an active center. Science 1997, 275, 362-366.

[14] Henriksen, A. ; Smith, A.T.; Gajhede, M. The structures of the horseradish peroxidase C-cyanide-ferulic and the ternary complex with cyanide suggest how peroxidases oxidize small phenolic substrates $J$. Biol. Chem. 1999, 274, 35005-35011.

[15] Rodrigues, L.C. ; Barbosa-Filho, J.M. Request for Patent PI 1101946-8 to INPI-Brazilian Institute of Intellectual Property, published in Revista da Propriedade Industrial (RPI), 2011, No. 2157.

[16] Néris, P.L.; Caldas, J.P.; Rodrigues, Y.K.; Amorim, F.M. ; Leite, J.A.; Rodrigues-Mascarenhas, S.; Barbosa-Filho, J.M.; Rodrigues, L.C.; Oliveira, M.R. Neolignan Licarin A presents effect against Leishmania (Leishmania major) associated with immunomodulation in vitro. Exp. Parasitol. 2013, 135,307-313.

[17] Nascimento, I.R.; Lopes, L.M.X.; Davin, L.B.; Lewis N.G. Stereoselective synthesis of 8,9Licarinediols, Tetrahedron 2000, 56, 9181-9193.



(C) 2017 ACG Publications. 